\title{
Gender, Disability and Empowerment In Institutions of Higher Learning in Zimbabwe
}

\author{
Maruzani Nyevero ${ }^{1}$, Mandipa Esau ${ }^{2}$, Matope Nogget ${ }_{5}^{3}$, Mugodzwa Tawanda ${ }^{4} \&$ \\ Chinyoka Tavuyanavo. \\ ${ }^{1}$ Lecturer, Gender Studies Department, Midlands State University, Zimbabwe \\ ${ }^{2}$ Lecturer ,Faculty of Law, Midlands State University, Zimbabwe \\ ${ }^{3}$ Lecturer, Gender Studies Department, Midlands State University, Zimbabwe \\ ${ }^{4}$ Lecturer, Gender Studies Department, Midlands State University, Zimbabwe \\ ${ }^{5}$ Graduate Teacher .Vumba Secondary School.Gokwe Zimbabwe
}

\begin{abstract}
This paper examines how gender relates to disability and empowerment. Throughout the world regardless of culture, disabled people have generally been seen as incapable of taking control of their own lives. There are three broad attitudes towards them among able bodied people, they may be regarded as lesser beings to be rejected, may be seen as objects of charity and they can be viewed with benevolent neutrality. This has led to a crude and overt rejection of disabled people. It is even worse for disabled women who face double discrimination, as women and as disabled women. In institutions of higher learning students with disabilities face challenges in their academic, welfare and financial matters. The argument in this paper is that every person operates more effectively when he/she feels valued and is able to value others. In the effort of society and individuals to empower people there is need to see themselves and the roles of disabled people positively so that disabled people can be given power to do so if other people relate to them positively. The paper puts more emphasis on the interrelationship of the law, gender and disability in all empowerment endeavors by governments and institutions of higher learning. Institutions need to ensure maximum responsiveness to gender and disability for the empowerment of all. The study concludes by recommending a social and political will to change negative attitudes to disability through a comprehensive gender analysis of various disability laws.
\end{abstract}

Key Words: disability, empowerment, gender, institutions of higher learning, law

\section{Introduction}

Throughout the world regardless of culture, disabled people have generally been seen as incapable of taking control of their own lives. There are three broad attitudes towards them among able bodied people, they may be regarded as lesser beings to be rejected, or they may be seen as objects of charity or maybe viewed with benevolent neutrality ${ }^{[1]}$.Societies glorify the perfect human being. Hitler ,in his time made an attempt to exterminate all disabled people. The Nazi Euthanasia Programme saw disabled people as useless eaters who made no contribution to society and a drain on resources ${ }^{[2]}$. In different societies disabled people are treated in various degrading ways that strip them of their dignity and respect .Dependent on others for their survival, disabled men and women frequently find it impossible to prevent the violation of their respect, dignity, and cultural identity. The unequal power relations make the disabled persons unable to influence or negotiate better terms for themselves with traders, governments and civil society.

The issue of disability cannot be looked at in isolation from other important issues of social relations. Most importantly we recognize that disabled people are not sexless: they are men and women with different interests and characteristics including age, economic status, aspirations and different experiences ${ }^{[3]}$. Empirical evidence show that disabled women have had less access than disabled men to the potential benefits that maybe obtained from national governments and non-governmental organisations which are set up to address practical and strategic needs of people ${ }^{[4]}$.To add to that the unique aspects of disabled women are at times not mentioned or totally ignored in most studies on disability.

The Salamanca Statement and Framework for Action on Special Needs Education adopted at the World Conference on Special Needs Education in June 1994 reaffirmed commitment of the world community to "Education for All" and urged governments to give the highest policy and budgetary priority to improve their education systems to enable them to include all children regardless of individual differences and difficulties. The United Nations (1994) in its "Standard Rules on the Equalization of Opportunities for Persons with Disabilities" urges Member States in Rule Number 6 to ensure that special needs education is made an integral part of the education system ${ }^{[5]}$. This is clear evidence that the international community recognises the need for nations to value the fundamental rights of persons with disabilities. 
Gender and disability are issues that are socially constructed; they are rooted in cultural, social, political, legal and economic factors. People with disabilities often lack the opportunities of the mainstream population and are usually among the most marginalised in any society ${ }^{[6]}$. Girls and women of all ages with any form of disability are among the more vulnerable and marginalized of society ${ }^{[7]}$. Cultural biases based on gender and disability limits the educational opportunities of disabled women and girls ${ }^{[8]}$. Those who promote the rights of persons with disabilities, and those promoting gender equality and the advancement of women are at times silent on women with disabilities. It is also important to note that Zimbabwe has neither signed, nor ratified the UNCRPD (United Nations Convention on the Rights of People With Disabilities) and the Optional Protocol. In 2008 a process of reviewing several pieces of legislation pertaining to disability was initiated, including the Disabled Persons Act, the Mental Health Act, and the Constitution, to align them with the UNCRPD.

\section{Who Is The Person With Disability (Pwd)}

Disability is a highly contentious subject area and there is no universally acceptable definition of who is a person with disability. According to The Convention on The Rights of Persons With Disabilities, Article 1(2008), persons with disabilities include those who have long-term physical, mental, intellectual, or sensory impairments which in interaction with various barriers may hinder their full and effective participation in society on an equal basis with others. A disability may be physical, cognitive, mental, sensory, emotional, and developmental or some combination of these. Disability is a complex phenomenon, reflecting an interaction between features of a person's body and features of the society in which he or she lives. ${ }^{[9]}$. In this paper the disabled person is one who has one or more of the above impairments.

\section{U.N. Efforts For Pwd}

While there are a range of policies and programs to promote educational equity for girls, these have largely overlooked disabled girls. On the other hand, strong disability rights and legislation has produced a range of efforts to promote equity for disabled children, few have been gender specific or have included gender specific components to address the unique barriers faced by disabled girls ${ }^{[10]}$. The following is a brief highlight of what the Convention on the Rights of Persons with Disabilities and its Optional Protocol says about people with disability.

On 13 December 2006, the General Assembly of the United Nations adopted the Convention on the Rights of Persons with Disabilities (CRPD), which ultimately entered into force on 3 May 2008. The formulation and the ultimate coming into force of the CRPD have been hailed as a great landmark in the struggle to reframe the needs and concerns of PWDs in terms of human rights ${ }^{[11]}$.The CRPD is highly commendable for its confirmation of persons with disabilities as rights-holders. Thus the human rights-based approach to disability which the CRPD follows actually empowers persons with disabilities by treating them as equal members of any given society.

The CRPD clearly states that the purpose of the Convention is 'to promote, protect and ensure the full and equal enjoyment of all human rights and fundamental freedoms by all persons with disabilities, and to promote respect for their inherent dignity' ${ }^{[12]}$. Clearly, the CRPD is geared towards the achievement of equality of opportunities for persons with disabilities, structural change, preparing persons with disabilities for greater participation, tackling of discrimination and the changing of social attitudes.

The CRPD strongly rejects the view that persons with disabilities are objects of charity or medical treatment and affirms them as subjects of rights with an ability to claim those rights as active members of society ${ }^{[13]}$

\section{The Zimbabwean Constitution And Disability Provisions}

Prior to 2005, the non-discrimination clause in the Constitution of Zimbabwe did not include disability as a ground upon which discrimination was prohibited. In 2005, the Constitution was amended so as to include physical disability as a prohibited ground of discrimination ${ }^{[14]}$. The Constitutional Amendment No. 17). Now the Constitution Section 23(2) provides that:

'... a law shall be regarded as making a provision that is discriminatory and a person shall be regarded as having been treated in a discriminatory manner if, as a result of that law or treatment, persons of a particular description by race, tribe, place of origin, political opinions, colour, creed, sex, gender, marital status or physical disability are prejudiced -

(a) by being subjected to a condition, restriction or disability to which other persons of another such description are not made subject; or

(b) by the according to persons of another such description of a privilege or advantage which is not accorded to persons of the first-mentioned description; and the imposition of that condition, restriction or disability or the 
according of that privilege or advantage is wholly or mainly attributable to the description by race, tribe, place of origin, political opinions, colour, creed, sex, gender, marital status or physical disability of the persons concerned.

Whereas the Constitutional Amendment is applauded for the sentiments behind it, one wonders if those who formulated it have thought carefully enough about the other forms of disability, especially mental, intellectual and sensory disabilities as provided for by the United Nations Convention on the Rights of Persons with Disabilities ${ }^{[15]}$. Furthermore, by treating men and women equally in the non-discrimination clause, the Constitution fails to cater adequately for the difference that gender presents. As is the norm in other jurisdictions, the Constitution also fails to address the plight of WWDs (Women With Disabilities) ${ }^{[16]}$ It would have been better if the Constitution had made a special provision which recognises that women and girls with disabilities are subject to multiple discrimination and therefore their rights to full and effective participation, to equality of opportunity with men and to non-discrimination have to be guaranteed.

From an empowerment perspective, the Constitution does not contain any provision on the need to take affirmative action in favour of PWDs except for a general provision that the implementation of affirmative action programmes for the protection or advancement of persons or classes of persons who have been previously disadvantaged by unfair discrimination shall not be construed as discrimination (Section 23(3)(g). This is a sad observation in that the equal treatment of PWDs, especially WWDs and their non-disabled counterparts may lead to injustice.

The South African Constitution intends, '[t]o promote the achievement of equality, legislative and other measures designed to protect or advance persons, or categories of persons, disadvantaged by unfair discrimination may be taken (South African constitution section 9(2)) and the Zimbabwe constitution may also include similar provisions. There is an urgent need to secure the advancement and empowerment of PWDs, especially WWDs, in order to ensure equal enjoyment of human rights ${ }^{[17]}$ and the acceleration of de facto equality (CEDAW Article 4(1)).

\subsection{The disabled persons act}

This is the principal statute when it comes to the recognition and protection of rights of persons with disabilities. It came into force on the $26^{\text {th }}$ of June 1992 and makes provisions for the welfare and rehabilitation of disabled persons. The Act establishes the National Disability Board (NDB) which is empowered to issue and serve adjustment orders to ensure access by all PWDs to mainstream public services. The Act states that where the NDB considers that any premises to which members of the public are ordinarily admitted or any premises in which services or amenities are ordinarily provided to members of the public are inaccessible to PWDs, it may serve an adjustment order requiring the owner of the premises or the provider of the service to undertake action at his/her own expense to secure reasonable access by PWDs. Due to the nature of many impairments, the inhospitable physical infrastructure, particularly in rural areas profoundly hampers PWDs from accessing mainstream public services like health, education, training, internet and other modes of communication.

Coming to the critical area of education, there is merely prohibition of discrimination against PWDs in employment (Section 9) and criminalization of discrimination against PWDs in education (section 10). Whereas the spirit underlying these provisions may appear to be progressive, it is saddening to note that the Act does not mention the right to employment of PWDs, especially WWDs. It is not surprising to note that although there are high rates of unemployment currently in Zimbabwe among PWDs and their non-disabled counterparts, WWDs are the worst affected ${ }^{[18]}$. Unfortunately the Act does embody an explicit provision on the right to employment of PWDs in general and of WWDs in particular.

The Act is also silent on other critical issues such as education despite the fact that school attendance is lower among PWDs, especially women and girls with disabilities as compared to their non-disabled counterparts. ${ }^{[19]}$ According to Combrinck ${ }^{[20]}$, girls with disabilities in Africa, Zimbabwe not being an exception, have even more limited access to education than their male counterparts, and accordingly, higher levels of illiteracy. Conclusively, the Act is gender retrogressive. SINTEF (2003) observed that $28 \%$ of children with disability never attend school,34\% of females with disability and $22 \%$ of males with disability never attend school compared with $12 \%$ of non disabled females and $8 \%$ of nondisabled males.

\subsection{The Social Welfare Act}

This Act provides for the granting of social welfare assistance to destitute and indigent persons and their dependents. The Act states that the physically and mentally handicapped automatically qualify to be destitute or indigent persons and are therefore eligible to receive social welfare assistance from the Department of Social Welfare (section 6).It is very clear that the Act was drafted alongside a misconception that disability is always associated with poverty (indigence). Disability may be associated with poverty but it is not always the 
case as some PWDs are capable of self-support and are sometimes in economically better situations as compared to their non-disabled counterparts.

Notwithstanding the above argument, it should be noted that PWDs have been represented to be amongst the World's 'poorest of the poor ${ }^{[21]}$ and this is equally true in the Zimbabwean context in which PWDs are highly vulnerable to poverty ${ }^{[22]}$ By making provision for social welfare assistance in the form of cash, rehabilitation, institutional nursing, boarding or foster home care, counselling services, provision of orthopaedic and orthoptic appliances, occupational training, pauper burials, the supply of food and clothing (Section 6) to PWDs, the Act assists in the reduction of poverty as advocated internationally. The Act is highly commendable to the extent that it assists in guaranteeing the right to an adequate standard of living and social protection of PWDs but the problem is with its implementation.

However, just like the Disabled Persons Act, it fails to cater for the special needs of WWDs in its provision relating to social welfare assistance. When it comes to employment, men with disabilities are at a better position to secure employment as compared to WWDs. This then means that WWDs are normally the ones in need of social welfare assistance. The Act should therefore have embodied a special provision on WWDs when it comes to social welfare assistance.

\section{Poverty And Disability}

There is a circular relationship between poverty and disability .Poverty causes disability, particularly in women and girls, who in the face of limited resources are more likely than their male counterparts to be deprived of basic necessities such as food and medicine ${ }^{[23]}$.Disability, in turn can contribute to poverty, because of the additional expenses that it can entail. The disabled girls are more likely to grow up in poor families, a reality that in itself places them at an educational disadvantage ${ }^{[24]}$.The Zimbabwean Government of National Unity,(GNU) launched a Medium Term Plan 2011-2016 which focuses mainly on economic growth and poverty reduction. The plan only mentions grants for PWDs and has no mention of empowerment or income generation for PWDs. PWDs were not specifically mentioned in the 2010 budget. In addition the 2010 MDG status report made no reference to PWD. Moreover the government has not instituted any projects or programmes which address the plight of PWDs.

\section{Gender, Empowerment And Disability}

Gender refers to the social attributes and opportunities associated with being male and female and the relationships between women and men and girls and boys, as well as the relations between women and those between men. These attributes, opportunities and relationships are socially constructed and are learned through the socialization processes. They are context/ time-specific and changeable ${ }^{[25]}$. Gender determines what is expected, allowed and valued in a woman or a man in a given context. In most societies there are differences and inequalities between women and men in responsibilities assigned, activities undertaken, access to and control over resources, as well as decision-making opportunities ${ }^{[26]}$.

The Convention on the Rights of Persons with Disabilities recognizes that women and girls with disabilities are often at great risk both within and outside the home, of violence, injury or abuse neglect or negligent treatment and exploitation. Women with disabilities encounter a myriad of physical and social obstacles. Women face barriers to full equality and advancement because of race, age, language, ethnicity, culture ,religion and disability ${ }^{[27]}$. Persistence of certain cultural and institutional barriers make women and girls with disability the victims of twofold discrimination: as women and as people with disability. The disadvantages come not only because they are disabled but because they are disabled women ${ }^{[28]}$. A 2004 report on Save The Children Norway found that $87.4 \%$ of girls with disabilities had been sexually abused.Approximately $48 \%$ of these girls were mentally challenged, $15.7 \%$ had hearing impairment and $25.3 \%$ had visible physical disabilities and of those sexually abused $52.4 \%$ tested HIV positive.

Disability studies have traditionally used a gender blind approach and have neglected the influence of gender in the lives of women and men with disabilities. There is a combined discrimination of gender and disability experienced by women who have disabilities. To add to that policies and practices in the field have not been designed to meet their specific needs ${ }^{[29]}$.Currently the Ministry of Youth Development, Gender and Employment Creation has not yet included persons with disabilities in its programmes.

Women's traditional roles as nurturers, mothers, wives, homemakers and lovers are usually not seen as appropriate for women with disabilities. Compared to both men with disabilities and non disabled women, women with disabilities are more likely never to marry, marry later and be divorced if they get married ${ }^{[30]}$. Although men and women with disabilities face similar violations of their inalienable human rights and fundamental freedoms, women with disabilities (WWDs) are at a further disadvantage ${ }^{[31]}$.

Despite the double marginalization of WWDs, the Zimbabwean legal system tends to follow a genderblind approach in as much as it totally neglects the influence of gender on the lives of men and women with disabilities. 
Empowerment covers a vast landscape of meanings, it can be defined as a process whereby individuals achieve increasing control of various aspects of their lives and participate in the community with dignity $^{[32]}$. It refers to a situation when individuals who are marginalised individually or collectively become aware of how power structures, processes and relations operate in their lives and gain the confidence and strength to challenge resulting inequalities Empowerment is a process which enables people, organisations, or groups who are powerless become aware of power dynamics at work in their life contexts and in them, develop skills and capacity for gaining some reasonable control over their lives, exercise control without infringing upon the rights of others and support the rights of others ${ }^{[33]}$.

Empowerment of disabled people refers to the creation and expansion of physically challenged peoples' knowledge,skills,decision making power and other power bases giving them the capability and capacity to exercise leadership and influence on their own. It refers to increasing political, social or economic strength of individuals and communities. It also refers to the empowered developing confidence in their own capacities. The process of empowerment is a key element in the improvement of the lives of people with disabilities especially disabled women and children. In the absence of supportive legislation people with disabilities have the following challenges:

- Decisions will be made for them and no one will bother including them in decision making

- They will be ignorant of the opportunities available to them which will limit their potential If the law is not clear on issues pertaining to disability it is difficult for people with disabilities to enjoy their full human rights. This will deny them of chances to make informed choices on their own.

- They will not have control over aspects of their lives, denying them of the chance to determine/decide their own destiny

- Prejudices and negative social constructions about disability will take away their capacity and right to act and influence decisions

All these challenges apply to all PWDs even students with disabilities in institutions of higher learning. Most of these challenges are a result of lack empowerment on issues pertaining to disability for both the disabled students and the non-disabled university community.

\section{Challenges Faced By Students With Disabilities}

Persons With Disabilities (PWDs) have been portrayed as a historically disadvantaged group ${ }^{[34]}$. This is equally true in the Zimbabwean context in which disability was and is still being viewed in a negative perception. Nearly 1.4 million people are living with disabilities in Zimbabwe ${ }^{[35]}$. Severe poverty and deprivation, limited political participation, discrimination, stigma and high levels of illiteracy are some of the social ills associated with PWDs. Available data indicate that women and girls with disabilities fare less well in the educational arena than either their disabled male or nondisabled female counterparts ${ }^{[36]}$. The global literacy rate for adults with disabilities is as low as $3 \%$ and $1 \%$ for women with disabilities ${ }^{[37]}$. Women and girls with disabilities face double discrimination based on gender and disability. Underlying the double discrimination is negative attitudes towards disability that often cut across cultures ${ }^{[38]}$. About 650 million people in the world or 10 per cent of the world's population - live with disabilities, and frequently encounter a myriad of physical and social obstacles ${ }^{[39]}$. Disabled women and girls are commonly stereotyped as sick, helpless, childlike, dependant, incompetent and asexual greatly limiting their options and opportunities ${ }^{[40]}$.

It is a commonly held misconception within the Zimbabwean society that PWDs are passive and economically unproductive, and therefore they are a burden upon the country as a whole ${ }^{[41]}$. These negative perceptions against disability are widespread and impact heavily on the rights of PWDs, especially their right not to be discriminated against.

A series of conferences and meetings on disability and the Millennium Development Goals (MDGs) were organised by governments, regional organizations and of PWDs. These meetings led to insightful discussion and recommendations on how to mainstream disability and include persons with disabilities in all MDGs. This came after realizing that disability and persons with disability are not mentioned in the MDGs nor in the targets and indicators that operationalise MDG efforts. Available information demonstrates the dearth of policies and programs that specifically address the educational needs of disabled girls and the failure of gender equity and disability equity programs to serve them. In institutions of higher learning there is need to understand the challenges faced by persons with disabilities which empowers the disabled persons, abled persons and the society at large. In the case of the University under study, the students with disabilities have the following socio-economic challenges

- Limited availability of reading material in large print or in Braille. Reading material which is available in the university is produced at the disability centre which may not be enough for all the students in their different Degree Programmes .

- Unavailability of assistive technology for VHS (visually handicapped students). 
- Discriminatory and negative attitude from lecturers and fellow students which results in lecturers failing to make necessary preparations for students with special needs. Attitudes from non disabled students may be developed to various myths held about people with disability.

- At times the curriculum is so inflexible and lecturers' preferences, techniques and methodologies may not meet the needs of persons with disabilities

- The absence of elevators to access lecture rooms above the ground floor may be a challenge for students with disabilities to access services offered in offices upstairs.

- The failure of the local health officers to offer specialized provisions for students who need special health care like the need for specialized lotions for albinism. There is a general non availability of health information in Braille and large print .Most health workers have misconceptions on the sexuality of persons with disability.

- The Ministry of Labour and Social Welfare, under which disability issues fall has no budget allocated for people with disabilities. Students have to make personal arrangements to get assistive technologies on their own. Most of the students end up using old fashioned technology which will compromise their academic performance.

\section{Conclusion}

There is a strong connection between gender, disability and empowerment .Empowered abled bodied people can understand and appreciate the role of disabled people in societies. On the other hand if people with disabilities are not empowered, disharmony and confusion will be the order of the day as people segregate each other according to the able bodied or disabled identity. Institutions of higher learning in Zimbabwe still fall behind in interlinking these three concepts. Though much has been said about equal access to education and equality of human rights for people with disabilities, most institutions of higher learning in Zimbabwe are yet to make their environments favourable for these equalities to be real. The paper concludes by strongly recommending the need for a ministry that deals with disability issues in Zimbabwe. It is hoped that this ministry will address challenges that people with disabilities face by lobbying for supportive legislation from government and putting in place relevant policies and programmes for people with disabilities. This will set the stage for institutions of higher learning to develop welcoming and supportive psychosocial environments through various training and support programmes.

\section{References}

[1]. Coleridge, R. (.1993) Disability, Liberation, and Development.Oxfam Print Unit U.K

[2]. Coleridge, R. (.1993) Disability, Liberation, and Development. Oxfam Print Unit U.K

[3]. Coleridge, R. (.1993) Disability, Liberation, and Development. Oxfam Print Unit U.K

[4]. Abu-Habib, L.(1997) Gender and Disability: Women's Experiences in the Middle East .Oxfam

[5]. Kisanji ,J (1995) The relevance of Indigenous Education Principles In The Formulation of Special Needs Education, A Paper presented at the fourth international Special Education Congress, Birmingham 10-13 April 1995

[6]. Despouy, L. Human Rights and Disabled Persons. Study Series 6)Centre for Human Rights.Geneve and UN. New York

[7]. Kisanji ,J (1995) The relevance of Indigenous Education Principles In The Formulation of Special Needs Education, A Paper presented at the fourth international Special Education Congress, Birmingham 10-13 April 1995

[8]. Rousso, H, (2000) Education For All: A gender and Disability Perspective. Background paper prepared for the Education For All Global Monitoring Report 2003/4

[9]. World Health Organization (WHO). (2004). Progress in reproductive health research, (No. 67). Retrieved from http://www.who.int/reproductive-health/hrp/progress/67.pdf

[10]. Rousso, H, (2000) Education For All: A gender and Disability Perspective. Background paper prepared for the Education For All Global Monitoring Report 2003/4

[11]. Kayess, \& French, P. (2008).Out of darkness into light ?Introducing the Convention on the Rights of Persons With Disabilities Human Rights. Law Review 8(1) 1-34

[12]. Section 4 of Act 5 of 2005, the Constitutional Amendment No.17: The principle of equality and dignity of human beings.

[13]. Convention on the Rights of Persons With Disabilities (2006) Article 1

[14]. Quinn, G. \& Degener, T. (2002). Human rights and disability: The current use and future potential of United Nations human rights instruments in the context of disability. New York: United Nations. Retrieved May 26, 2007, from http://www.unhchr.ch/html/menu6/2/disability.doc

[15]. CEDAW (1979) Convention on the Elimination of All Forms of Discrimination against Women. Article 1(4)Three United Nations Plaza, New York: New York 10017 USA

[16]. Eide,A.H,van Rooy,G, \& Leobe, M.E.(2001) Living conditions among people with activity limitations in Namibia: a representative, national study. Oslo SINTEF 2003b(http://safod.org/Images/LCNamibia.pdf)Accessed on 29 November 2011

[17]. Eide,A.H,van Rooy,G, \& Leobe, M.E.(2001) Living conditions among people with activity limitations in Namibia: a representative, national study. Oslo SINTEF 2003b(http://safod.org/Images/LCNamibia.pdf)Accessed on 29 November 2011

[18]. Combrinck. (2008). The Hidden Ones: Children With disabilities in Africa and the Right to Education In: SLOTH-NIELSON, J (Ed) Children's Rights in Africa: A Legal Perspective. Aldershot: Ashgate pp299-322. http://www.surjournal.org/eng/conteudos/getArtigoi4.php?artigo=14, artigo-17htm

[19]. Thornberry, P. (1991) International Law and the Rights of Minorities .Clarendon Press ,Oxford

[20]. Choruma,T, T.(2006) “The forgotten tribe: People with disabilities in Zimbabwe ’Progressio Report, Progressio London

[21]. Groce, N, (1997) Women with Disability in the developing world. Journal of Disability Policy Studies 8,1\&2 pp178-192 
[22]. Rousso, H, (2000) Education For All: A gender and Disability Perspective. Background paper prepared for the Education For All Global Monitoring Report 2003/4

[23]. UN (2000) UN Office of the Special Advisor on Gender Issues and Advancement of Women: 10/05/00

[24]. UN (2000) UN Office of the Special Advisor on Gender Issues and Advancement of Women: 10/05/00

[25]. Women Watch-Information(2011) Resources on Gender Equality and Empowerment of Women .United Nations

[26]. Grobbelaar-du Plessis. (2007) 'The African women with disabilities: The victims of multilayered discrimination' (2007) 22 South Africa Publiekreg/Public Law 405

[27]. Simon, B.L.(1998) Never married old women with disability .A majority experience. In M, Fine \& Asch, A. (Eds) Women with Disabilities. Essays in psychology, culture and politics .Pdiladelphia,P.A.Temple University Press.

[28]. Women Watch-Information(2011) Resources on Gender Equality and Empowerment of Women .United Nations

[29]. Traustadottir. (1998) 'Women with disabilities: The double discrimination: Part 1' available at http://thechp.sy.edu/womdis1.htm (accessed 19 September 2011).

[30]. Lord, J \& Hutchinson. (1993) The process of Empowerment: Implications for theory and practice. Canadian Journal of community Mental Health .12(1) pp5-22

[31]. Hannan, (2003) Transforming Empowerment and Gender Mainstreaming :www.un.org/womenwatch accessed 10 May 2013

[32]. Ngwena, C. (2006). Deconstructing the definition of 'disability' under the Employment Equity Act: Social deconstruction. South African Journal of Human Rights, 22, 613-646.

[33]. Lang R. \& Charowa G. (2007) DFID Scoping Study: Disability Issues in Zimbabwe Final Report, London: DFID 2007

[34]. Rousso, H, (2000) Education For All: A gender and Disability Perspective. Background paper prepared for the Education For All Global Monitoring Report 2003/4

[35]. Choruma,T, T.(2006) “The forgotten tribe: People with disabilities in Zimbabwe”Progressio Report ,Progressio London

[36]. Rousso, H, (2000) Education For All: A gender and Disability Perspective. Background paper prepared for the Education For All Global Monitoring Report 2003/4

[37]. Women Watch-Information(2011) Resources on Gender Equality and Empowerment of Women .United Nations

[38]. Rousso, H, (2000) Education For All: A gender and Disability Perspective. Background paper prepared for the Education For All Global Monitoring Report 2003/4

[39]. Constitution of Zimbabwe Amendment No. 17 Bill, 2005 (hb2005)-Representations made by the Zimbabwe Human Rights NGO Forum to the Portfolio Committee on Justice, Legal and Parliamentary Affairs' available on http://reliefweb.int/sites/ reliefweb.int/node/181818/pdf (accessed 19 September 2011)

\section{Legislation used}

- $\quad$ Act 5 of 1992, Disabled Persons Act [Chapter 17:01].

- $\quad$ Act 22 of 1971, the Children's Act [Chapter 5:06].

- Act 10 of 1988, the Social Welfare Act [Chapter 17:06].

- $\quad$ Act 22 of 1971, the State Service (Disability Benefits) Act [Chapter 16:05].

- Section 4 of Act 5 of 2005, the Constitutional Amendment No.17: The principle of equality and dignity of human beings.

- The Constitution of Zimbabwe, 1996 edition.

- $\quad$ The Constitution of South Africa [Chapter 9:2] 